\title{
openheart Prospective multicentre cohort study of transthoracic echocardiography provision in the South West of the UK during the first wave of SARS- CoV-2 pandemic
}

Rebecca Lucy Crook (D) , ${ }^{1}$ Howell Williams, ${ }^{1}$ Mary Green, ${ }^{1}$ Stewart Brown, ${ }^{1}$ Richard Morris, ${ }^{1}$ Hannah Fletcher, ${ }^{1}$ Sarah Walters, ${ }^{1}$ Catherine Walsh, ${ }^{1}$ Anna Price, Samantha King, ${ }^{1}$ Christopher James McAloon ${ }^{1,2}$

\section{- Additional material is published online only. To view please visit the journal online (http://dx.doi.org/10.1136/ openhrt-2020-001409). \\ To cite: Crook RL, Williams H, Green $\mathrm{M}$, et al. Prospective multicentre cohort study of transthoracic echocardiography provision in the South West of the UK during the first wave of SARS-CoV-2 pandemic. Open Heart 2021;8:e001409. \\ doi:10.1136/ \\ openhrt-2020-001409}

Received 3 August 2020 Revised 23 December 2020 Accepted 8 January 2021

\section{Check for updates}

(c) Author(s) (or their employer(s)) 2021. Re-use permitted under CC BY-NC. No commercial re-use. See rights and permissions. Published by BMJ.

${ }^{1}$ Cardiology, Gloucestershire Hospitals NHS Foundation Trust Gloucester, UK

${ }^{2}$ Cardiology, University Hospitals Birmingham NHS Foundation

Trust, Birmingham, UK

Correspondence to Dr Rebecca Lucy Crook; rebecca.crook2@nhs.net

\section{ABSTRACT}

Aims It was predicted internationally that transthoracic echocardiography (TTE) would be vital during the SARSCoV-2 outbreak. We therefore, designed a study to report the demand for TTE in two large District General Hospitals during the rise in the first wave of the SARS-CoV-2

pandemic in the UK. A primary clinical outcome of 30-day mortality was also assessed.

Methods The TTE service across two hospitals was reconfigured to maximise access to inpatient scanning. All TTEs of suspected or confirmed SARS-CoV-2 patients over a 3-week period were included in the study. All patients were followed up until at least day 30 after their scan at which point the primary clinical outcome of mortality was recorded. Comparative analysis based on mortality was conducted for all TTE results, biochemical markers and demographics.

Results 27 patients with confirmed SARS-CoV-2 had a TTE within the inclusion window. Mortality comparative analysis showed the deceased group were significantly older (mean 68.4 , SD 11.9 vs 60.5 , SD 13.0, $\mathrm{p}=0.03$ ) and more commonly reported fatigue in their presenting symptoms $(29.6 \%$ vs $71.4 \%, p=0.01)$. No other differences were identified in the demographic or biochemical data. Left ventricular systolic dysfunction was noted in $7.4 \%$ of patients and right ventricular impairment or dilation was seen in $18.5 \%$ patients. TTE results were not significantly different in mortality comparative analysis. Conclusion This study demonstrates an achievable approach to TTE services when under increased pressure. Data analysis supports the limited available data suggesting right ventricular abnormalities are the most commonly identified echocardiographic change in SARS-CoV-2 patients. No association can be demonstrated between mortality and TTE results.

\section{INTRODUCTION}

The novel coronavirus 2019 (SARS-CoV-2) is the third beta-coronavirus to have reached pandemic level spread, having taken the lives of over 2.1 million people worldwide

\section{Key questions}

What is already known about this subject?

- SARS-CoV-2 infection is associated with increased mortality in those with underlying cardiovascular disease, as well as cardiac injury. Very few studies, however, have assessed the echocardiographic findings of this patient group. Documented abnormalities have included large pericardial effusions and right ventricular dilation or impairment.

What does this study add?

- This study is the first to describe how an echocardiography service can be adapted to manage an increase in demand associated with the SARS-CoV-2 pandemic. The findings support previous results suggesting right ventricular anomalies are the most common abnormalities to be found in SARS-CoV-2 patients but question the association between viral infection and pericardial effusions.

How might this impact on clinical practice?

- The paper presented acts as a guide to rapid upscaling of echocardiographic services in the context of the SARS-CoV-2 pandemic. This can be easily adapted to the readers' own hospital. The findings also support the use of new right ventricular dysfunction as a marker of SARS-CoV-2-related cardiac injury.

at point of writing. ${ }^{1}$ Specific patient risk factors including older age, ${ }^{2-4}$ male gender, ${ }^{5}$ diabetes mellitus, ${ }^{26-8}$ hypertension ${ }^{24679}$ and cerebrovascular disease 2 $^{49}$ are associated with higher risk of intensive care (ITU) stay or mortality when infected with SARS-CoV-2. However, the most significant comorbidity associated with mortality from SARS-CoV-2 is cardiovascular disease. ${ }^{6}$ Cardiac injury (CI) has also been repeatedly reported in patients with SARS-CoV-2 with an incidence rate of 
CI of 7.2\%-27.8\% in all inpatients..$^{2}{ }^{39-12}$ Those with cardiovascular disease are at higher risk of CI. ${ }^{13}$ Shi $e t$ $a l$, however, identified CI (defined as by troponin I levels $>99$ th percentile of upper reference limit) was an independent risk factor for SARS-CoV-2-related mortality. ${ }^{10}$

Whilst evidence surrounding the cardiac implications of SARS-CoV-2 infection is building, transthoracic echocardiography (TTE) has been viewed internationally as a critical test for those hospitalised with SARS-CoV-2, especially those requiring ITU admission. ${ }^{13-15}$ Demand has been expected to be high nationally and internationally for TTE during the pandemic in healthcare settings. ${ }^{13-15}$

The aim of this study was to report the demand and requests for TTE in two large District General Hospitals during the rise in the first wave of the SARS-CoV-2 pandemic in the UK. Additionally, the study aimed to give an overview of the clinical and echocardiographic features of our cohort, with a particular focus on any association between these features and mortality.

\section{METHODS}

\section{Study design}

A prospective observational cohort study was performed across two large UK District General Hospitals in the South West of England. All SARS-CoV-2 suspected or confirmed inpatients who required a TTE between 25 March 2020 and 16 April 2020 were included. Participants were excluded if the TTE was a repeat of a previous study during that admission. Patients were observed for 30 days after TTE. While the main aim of this study was to give an overview of the lived experience of echocardiographic services during the first waves of the SARS-CoV-2 pandemic, the clinical outcome of all-cause mortality at 30 days post TTE in SARS-CoV-2 positive patients was used to demonstrate the features of our cohort. For patients with COVID-19 disease, the need for individual consent was waived by national UK guidance covering research during the COVID-19 pandemic as the data were collected by members of usual clinical care teams for the primary purposes of clinical need and/or locally approved service evaluation. The Gloucestershire Hospitals National Health Service Foundation Trust audit and governance committee gave permission to undertake this study.

\section{Data collection}

Anonymised demographic and clinical data were collected from the electronic patient record. Paper case notes were not able to be reviewed due to the requirement to enter a SARS-CoV-2 positive areas. Vascular biomarker and blood film results were collected from the initial admission with the exception of high sensitivity troponin. When a troponin was assessed on admission this has been included, otherwise the earliest troponin assessed for the patient has been collected alongside the peak value during admission. A positive diagnosis of SARS-CoV-2 was based on an upper-respiratory tract swab (both oropharynx and nasopharynx) with laboratory confirmed virus using reverse transcription PCR.$^{16}$ Admissions to ITU, duration of admission and requirement for invasive/non-invasive ventilation were recorded.

\section{Transthoracic echocardiography}

In order to prepare for the local wave of SARS-CoV-2, TTE services at both centres were actively reconfigured to allow maximal inpatient capacity including daily weekday attendance in both ITUs. Additional weekend cover was also provided on an ad hoc basis. Capacity for this was created through repeat triaging of all outstanding outpatient TTE requests using a traffic light system to denote urgency. This was undertaken by a combination of British Society of Echocardiography (BSE) accredited sonographers and clinicians and resulted in the rescheduling of approximately 300 TTEs plus an additional approximately 300 other cardiac investigations (eg, ambulatory rhythm monitoring devices and transoesophageal echocardiograms).

Both institutions implemented a TTE COVID-19 scanning standard operating procedure (online supplemental appendix 1) in line with the BSE COVID-19 pathway. ${ }^{17}$ A level 1 BSE scan was performed on all patients with suspected or confirmed COVID-19 wearing national standards personal protective equipment to maximise protection and minimise contact time for the echocardiographer. ${ }^{18}$ To further reduce infection risk to sonographers, only fit tested sonographers undertook scans of confirmed or suspected SARS-CoV-2 and all required measurements were taken on returning to the cardiac investigations department. Dedicated GE Vivid q and S6 ultrasound machines (GE Healthcare, Horten, Norway) were allocated to perform all confirmed or suspected COVID-19 scans. All TTE studies were anonymously reviewed by a single BSE accredited echocardiographer. Quality was assessed according to published standards as set out by Nagata et $a l^{19}$

Focused intensive care echocardiography scans were not included in this study as BSE level 1 protocol is not completely adhered too, meaning standardisation for the study could not be achieved.

\section{Statistical analysis}

Statistical analysis was performed using SPSS, V.22.0 (IBM). Categorical variables were reported as frequency and percentages. Comparison analyses for categorical data were performed using the $\chi^{2}$ or Fisher's exact tests, dependent on appropriateness. Continuous data underwent histogram plots for assessment of normality. Normally distributed data were reported as mean and SD and comparative analysis performed using independent t-tests. Non-normally distributed data were reported as median (full range) and compared using Mann-Whitney $\mathrm{U}$ test. A posterior probability model, logistic regression was conducted for the covariates of age, gender and echocardiographic findings. Inclusion of further covariates was prohibited by the small sample size. A $p<0.05$ 
Table 1 Demographics and baseline characteristics of all included patients

\begin{tabular}{|c|c|c|c|c|}
\hline \multirow[b]{2}{*}{ Characteristic } & \multirow[b]{2}{*}{ All patients $(n=30)$} & \multicolumn{3}{|c|}{ SARS-CoV-2 positive $n=27$} \\
\hline & & Died $(n=7)$ & Survived $(n=20)$ & $P$ value \\
\hline Age (median, range) & $64.5(37-80)$ & $68.4(64-73)$ & $60.5(37-80)$ & 0.03 \\
\hline Female $(\mathrm{n}, \%)$ & $8(26.7)$ & 0 & $7(35.0)$ & 0.14 \\
\hline \multicolumn{5}{|l|}{ Comorbidities, N (\%) } \\
\hline Hypertension & $13(43.3)$ & $3(42.9)$ & $8(40.0)$ & \\
\hline Ischaemic heart disease & $1(3.3)$ & 0 & $1(5.0)$ & 1.00 \\
\hline Heart failure & $2(6.7)$ & 0 & $1(5.0)$ & 1.00 \\
\hline Diabetes mellitus (all types) & $6(20.0)$ & $1(14.3)$ & $5(25.0)$ & 1.00 \\
\hline Cerebrovascular disease & $2(6.7)$ & $1(14.3)$ & $1(5.0)$ & 0.46 \\
\hline Chronic respiratory disease & $7(23.3)$ & $1(14.3)$ & $6(30.0)$ & 0.63 \\
\hline Chronic hepatological disease & $1(3.3)$ & 0 & 0 & - \\
\hline Chronic rheumatological disease & $3(10.0)$ & $1(14.3)$ & $2(10.0)$ & 1.00 \\
\hline Malignancy & $4(13.3)$ & $1(14.3)$ & $3(15.0)$ & 1.00 \\
\hline \multicolumn{5}{|l|}{ Treatments, N (\%) } \\
\hline ITU admission & $22(73.3)$ & $6(85.7)$ & $14(70.0)$ & 0.63 \\
\hline Days on ITU* & $10.5(12.1)$ & $9.0(7.9)$ & $13.3(10.1)$ & 0.32 \\
\hline CPAP† & $9(30.0)$ & $3(42.9)$ & $4(23.5)$ & 0.37 \\
\hline Intubation and ventilation & $20(66.7)$ & $6(85.7)$ & $13(65)$. & 0.63 \\
\hline
\end{tabular}

*Values in this row represent mean and SD.

†Data unavailable for three patients-all SARS-CoV-2 positive and in the survived group, $\mathrm{N}$, therefore, is 17 in this group.

CPAP, continuous positive airway pressure.

was considered statistically significant for all analysis. Mortality comparison was conducted including only patients which were SARS-CoV-2 positive within the study window.

\section{RESULTS}

\section{Patient characteristics and outcomes}

Thirty SARS-CoV-2 suspected or confirmed positive patients were referred for an inpatient TTE, 27 of which proved to have been positive during the study window. Of the positive group, mean age was $62.6 \pm 11.9$ years, 7 (25.9\%) were female and 7 (25.9\%) died within 30 days of their TTE. Table 1 provides full details of patient characteristics. Notably the group of those who died (mean $68.4 \pm 11.9$ years) compared with those who survived (mean $60.5 \pm 13.0$ years) were significantly older $(\mathrm{p}=0.03)$.

Among the SARS-CoV-2 positive patients, the most common presenting symptoms were cough (21 patients, $77.8 \%$ ), dyspnoea (18 patients, 66.7\%) and fever (15 patients, $51.9 \%$ ). Figure 1 displays full details of presenting symptoms. No significant differences were identified in presenting symptoms during mortality comparison analysis with the exception of fatigue $(p=0.01)$. The most common comorbidities were hypertension (11 patients, $40.7 \%)$, chronic respiratory disease (7 patients, $25.9 \%$ ) and diabetes mellitus (6 patients, $22.2 \%$ ), with no significant difference between those that survived and died at 30 days. Table 1 contains complete details of comorbidities.
Of the 27 patients within the SARS-CoV-2 positive cohort $13(48.1 \%)$ were inpatients at day 30, with six in ITU and seven in general medical wards. The final seven $(25.9 \%)$ patients had been discharged home. With regard to treatment in the SARS-CoV-2 positive population, seven $(25.9 \%)$ patients required continuous positive airway pressure during the data collection window, three (42.9\%) of which died within the 30 days. Twenty ( $74.1 \%$ ) patients required an ITU stay during the data collection window, $19(70.4 \%)$ of which were intubated and ventilated. Mean ITU stay was 12.2 days (SD 9.70). There was no significant difference between treatment modalities

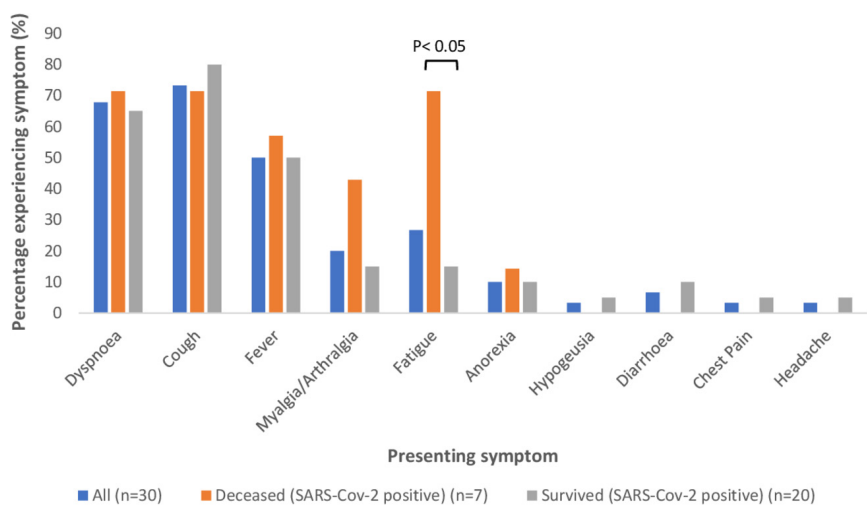

Figure 1 Frequency of presenting symptoms of patient cohort. 


\begin{tabular}{|c|c|c|c|c|}
\hline Characteristic & All $(\mathrm{N}=27)$ & Died ( $N=7)$ & Survived $(\mathrm{N}=20)$ & $P$ value \\
\hline \multicolumn{5}{|c|}{ Biomarkers, median (range) or mean (SD) } \\
\hline Haemoglobin (g/L) & $130.6(21.7)$ & $129.3(22.7)$ & $131.1(21.9)$ & 0.85 \\
\hline C reactive protein $(\mathrm{CRP})^{\star}(\mathrm{mg} / \mathrm{L})$ & $160.6(93.5)$ & $178.3(110.4)$ & $154.1(88.9)$ & 0.62 \\
\hline Creatinine $(\mu \mathrm{mol} / \mathrm{L})$ & $89.0(53.0-1197.0)$ & $89.0(60.0-1197.0)$ & $86.00(53.0-666.0)$ & 0.98 \\
\hline First troponin† (ng/L) & $17.6(2.5-3239.0)$ & $10.5(9.4-18.6)$ & $21.7(2.5-2329.0)$ & 0.21 \\
\hline Day of first troponin $\dagger$ & $1.0(1.0-17.0)$ & $1.5(1.0-2.0)$ & $1.0(1.0-17.0)$ & 0.70 \\
\hline Peak troponin† (ng/L) & $48.0(5.1-3239.0)$ & $24.0(10.7-521.0)$ & $53.60(5.1-3239.0)$ & 0.47 \\
\hline Day of peak troponin† & $10.2(8.7)$ & $10.0(8.5)$ & $10.2(9.0)$ & 0.96 \\
\hline
\end{tabular}

*Total $\mathrm{N}=25$ as not all patient's had CRP assessments, both missing values in the surviving group.

†Total $n=21$ as not all patient's had troponin assessments, presence of missing values split evenly between the deceased and surviving groups.

or in the duration of ITU stay in mortality comparison analysis. Table 1 displays full details of treatments.

\section{Biomarkers}

Hs-cTnT was performed in $21(77.9 .6 \%)$ SARS-CoV-2 positive patients, of which four had a single measurement. Table 2 shows the full range of biomarkers in SARS-CoV-2 positive cases. Median initial and peak troponin values were $17.6 \mathrm{ng} / \mathrm{L}(2.5-3239 \mathrm{ng} / \mathrm{L})$ and $48.0 \mathrm{ng} / \mathrm{L}$ (5.1$3239 \mathrm{ng} / \mathrm{L})$, respectively. Eighty-one per cent of patients had a troponin above the 99th percentile of the upper reference limit. One significant outlier value of 3239.0 $\mathrm{ng} / \mathrm{L}$ was recorded in a patient who presented with an ST-elevation myocardial infarction. No significant difference for either troponin value was identified in mortality comparison analysis.

\section{Transthoracic echocardiogram}

Thirty-one TTEs were performed during the data collection window, one of which was a repeat scan for a patient already included in the dataset and therefore was excluded from further analysis. Table 3 outlines the quality, location and indications for all TTEs. The most common indications were assessment for possible heart failure, largely in terms of left ventricular (LV) function $(\mathrm{n}=13,43.3 \%)$, and right heart function and strain, often querying a pulmonary embolus $(\mathrm{n}=8,26.7 \%)$. Eight patients had further imaging to investigate for a possible pulmonary embolism (largely CT pulmonary angiograms) of which two were positive (one at segmental and one at subsegmental level). Both of the positive cases had normal right ventricular size and function. The majority of the TTEs performed were of a good image quality (13 patients, $43.3 \%$ ), with the remainder being fair (13 patients, $43.3 \%$ ). Table 4 demonstrates the findings from the TTEs. Binomial logistic regression found no significant association between age, gender and echocardiographic result (see online supplemental appendix 2).

\section{DISCUSSION}

The SARS-CoV-2 global pandemic has seen rapid reconfiguration of services across the world to meet the predicted demand. Echocardiography was predicted to be, and has been, an essential service across healthcare to assess the potential cardiac manifestations of SARS-CoV-2. ${ }^{13-15} 20$ In the UK, the BSE outlined the expectation of higher demand and having to adapt normal routines to meet the demand. ${ }^{17}$ During the first wave of the pandemic in the UK, two centres in the South West of England performed 31 focused TTE on suspected or positive SARS-CoV-2 patients. This service was delivered through the successful

Table 3 Quality, location and. indications for all TTEs performed $(n=30)$

\begin{tabular}{lc}
\hline Parameter & N (\%) \\
\hline Quality & $13(43.3)$ \\
\hline Good & $8(26.7)$ \\
\hline Fair & $7(23.3)$ \\
\hline Poor & $2(6.7$ \\
\hline Not documented & \\
\hline Location & $22(74.2)$ \\
\hline ITU & $2(6.5)$ \\
\hline General medical ward & $2(6.5)$ \\
\hline Acute medical unit & $1(3.2)$ \\
\hline Emergency department & $3(9.7)$ \\
\hline Not documented & \\
\hline Indication* & $13(43.3)$ \\
\hline Possible heart failure & $8(26.7)$ \\
\hline Right heart function and possible strain & $5(16.7)$ \\
\hline Overall cardiac function in ITU & $4(13.3)$ \\
\hline $\begin{array}{l}\text { Possible viral-related cardiac injury/ } \\
\text { myocarditis }\end{array}$ & $3(10.0)$ \\
\hline $\begin{array}{l}\text { Possible structural heart disease/valve } \\
\text { abnormalities }\end{array}$ & $2(6.7)$ \\
\hline Abnormal ECG & $1(3.3)$ \\
\hline Possible intra-cardiac thrombus & \\
\hline
\end{tabular}

*Many TTE requests asked multiple questions, all of which have been expressed in the indications data displayed.

ITU, intensive treatment unit; TTE, transthoracic echocardiography. 
Table 4 TTE findings for SARS-CoV-2 positive patients

\begin{tabular}{|c|c|c|c|c|}
\hline Characteristic & All $(n=27)$ & Died $(n=7)$ & Survived $(n=20)$ & $P$ value \\
\hline \multicolumn{5}{|l|}{ Left ventricular ejection fraction, $\mathrm{N}(\%)$} \\
\hline$>55 \%$ & $22(81.5)$ & $6(85.7)$ & $16(80.0)$ & 1.00 \\
\hline $45 \%-55 \%$ & 0 & 0 & 0 & \\
\hline $35 \%-44 \%$ & $2(7.4)$ & 0 & $2(10.0)$ & \\
\hline$<35 \%$ & 0 & 0 & 0 & \\
\hline Not documented & $3(11.1)$ & $1(14.3)$ & $2(10.0)$ & \\
\hline \multicolumn{5}{|c|}{ Left ventricular size and contractility, N (\%) } \\
\hline Normal size & $21(77.8)$ & $7(100.0)$ & $14(70.0)$ & 0.44 \\
\hline Left ventricular hypertrophy & $2(7.4)$ & 0 & $2(10.0)$ & \\
\hline Left ventricular dilation & 0 & 0 & 0 & \\
\hline Regional wall motion abnormalities & $4(14.8)$ & 0 & $4(20.0)$ & \\
\hline \multicolumn{5}{|l|}{ Right ventricular size and function, $\mathrm{N}(\%)$} \\
\hline Normal size and function & $22(81.5)$ & $7(100.0)$ & $15(75.0)$ & 0.66 \\
\hline Normal size, impaired function & 0 & 0 & 0 & \\
\hline Dilated, normal function & $1(3.7)$ & 0 & $1(5.0)$ & \\
\hline Dilated, impaired function & $4(14.8)$ & 0 & $4(20.0)$ & \\
\hline \multicolumn{5}{|l|}{ Other findings, $\mathrm{N}(\%)$} \\
\hline Pericardial effusion $>1 \mathrm{~cm}$ & 0 & 0 & 0 & 1.00 \\
\hline Pericardial effusion $<1 \mathrm{~cm}$ & $1(3.7)$ & 0 & $1(5.0)$ & \\
\hline Valve disease & $2(7.4)$ & 0 & $2(10.0)$ & 1.00 \\
\hline
\end{tabular}

TTE, transthoracic echocardiography.

rapid reconfiguration of TTE services to meet requirements. While it is always necessary to justify an investigation, never has this been truer than in the context of pandemic infectious disease. The experience described serves to highlight how close liaison with departments, for example, through daily visitation of ITU, can serve to prioritise patients with greatest need while minimising unnecessary exposure to sonographers. This is in-keeping with data presented by Ward et al which highlights an increase in the 'appropriateness' of TTE requests as a result of the pandemic. ${ }^{20}$

The role of echocardiography in the care of SARS-CoV-2 patients has varied across hospitals and countries during the pandemic. Drake $e t a l$, for example, describe its use in the following scenarios: assessment of patient with respiratory presentations which may or may not be secondary to SARS-CoV-2 infection; assessment for cardiac dysfunction in ITU patients with SARS-CoV-2; evaluation of volume status in patients with SARS-CoV-2. ${ }^{13}$ This not standard practice in the UK. Given the increased work load experienced by the hospitals during the pandemic, this would have been impractical to institute and would have significantly increased exposure to sonographers. The prime use of TTE in the paper presented better fits the latter two indications described above, as a large majority were performed in ITU with the primary indication of possible heart failure. A smaller number were requested exclusively for assessment of cardiac function in ITU patients; this it likely to near equate with assessment of volume status as described by Drake $e t a l^{13}$

This paper adds to the limited data available regarding echocardiographic abnormalities identified in SARS-CoV-2 patients. The results presented mirror the few existing publications which have demonstrated rates of left ventricular systolic dysfunction of $5.4 \%-11 \%,{ }^{2122}$ in keeping with the $7.4 \%$ identified above. However, the LV dysfunction identified in our positive cohort were related to other mechanisms. There is no clear mechanism of CI from SARS-CoV-2 in these patients.

The most common abnormality seen in the existing literature is often right ventricular dysfunction or dilation as demonstrated here. ${ }^{21} 23$ The exception to this is the high rate of pericardial effusions $>0.5 \mathrm{~cm}(19.6 \%)$ seen in one study during the Wuhan outbreak. ${ }^{22}$ The result of this study, therefore, adds to the existing evidence suggesting significant myocarditis is not a common feature of SARS-CoV-2 infection as had been previously feared. ${ }^{3} 22$ Whether the right ventricular systolic dysfunction can explain the raised troponins seen in many SARS-CoV-2 patients $^{23} 79-12$ and the increased risk of mortality ${ }^{10}$ is debatable as correlations with raised troponins have been conflicting. ${ }^{21}{ }^{23}$ Certainly, the lack of difference between the TTE findings in the above mortality analysis would not support this as a theory. Comparatively, another paper to conduct mortality analysis on TTE data identified only low left ventricular ejection fraction, raised $\mathrm{E} / \mathrm{e}^{\prime}$ ratio, 
elevated right ventricular end diastolic area and higher Tei index as being associated with fatality. ${ }^{23}$ It is likely that the small sample size of the cohort presented explains the lack of association between echocardiographic findings and mortality which has been found by others. ${ }^{23}$

The pathophysiology of CI associated with SARS-CoV-2 is likely multifactorial. Potential mechanisms for right ventricular dysfunction include elevated pulmonary vascular resistance secondary to higher left atrial pressure, pulmonary vascular disease (including pulmonary emboli) and parenchymal lung disease. ${ }^{21}{ }^{23}$ With regard to CI overall, many have cited indirect damage as a result of the exaggerated inflammatory response seen in SARS-CoV-2 ${ }^{24} 25$ as a causative pathway, ${ }^{26-30}$ mediated in part by the resultant prothrombotic state and vascular inflammation (and so plaque instability) generated. ${ }^{27} 29$ Evidence for this can be seen in the correlation between elevated cardiac biomarkers and ECG abnormalities with higher inflammatory markers. ${ }^{30}$

Direct viral infection of myocytes via ACE2 receptors has also been widely theorised to be responsible for SARS-CoV-2-related CI. ${ }^{26}{ }^{28-31}$ Given severe acute respiratory syndrome also acts via AEC2 receptors ${ }^{32} 33$ and has been identified in cardiomyocytes on postmortem analysis $^{3435}$ this seems plausible. By comparison, while fatalities of the SARS-CoV-2 pandemic have shown cardiac pathological changes from mild interstitial inflammation to myocyte necrosis, ${ }^{29}$ there is no evidence as yet of SARS-CoV-2 identified within cardiac tissue of patients in postmortem studies. One study has, however, successfully demonstrated direct infection of human cardiomyocytes in vitro and additionally found this occurs in an ACE2 and cathepsin-dependent fashion. ${ }^{36}$

Finally, cardiac stress secondary to hypoxaemia and resultant oxygen supply and demand mismatch, ${ }^{30} 3137$ stress-induced cardiomyopathy, ${ }^{29}{ }^{31}$ viral induced vasculitis $^{31}$ and iatrogenic causes secondary to drug side effects ${ }^{2837}$ have all be debated as possible mechanisms for SARS-CoV-2-related CI.

\section{Limitations}

Our study has several limitations, which must be considered when interpreting the results. First, the number of patients included is small, most likely as the South West of England had relatively low rates of SARS-CoV-2 compared with other UK regions during the first wave ${ }^{38}$ As the aim of the study was to demonstrate the demand and service adaptions required during the increase in cases of SARS-CoV-2, data collection was only undertaken during this peak escalation window. The resultant small numbers are likely to explain the higher incidence of right ventricular abnormalities and higher peak troponin in the group surviving at day 30 . The design of the study also prohibited the performing of echocardiograms on day one of admission in order to obtain a baseline image set, as was conducted in one published study. ${ }^{23}$ While this has obvious benefits, on average the patients included had experienced symptoms for 9 days at the point of admission. As a result, it is highly possible that even day one TTEs may already reflect damage resulting from SARS-CoV-2 infection.

A second limitation of the study was the absence of blinding of the echocardiographers to the patient infection status potentially introducing interpretation bias. A second blinded reviewer confirmed the findings generated to attempt to partially overcome this issue. Third, only BSE level 1 scans were performed as per the local and national standard operating procedure.$^{17}$ No point of care ultrasound scans was included, potentially limiting our numbers of patients. However, standardisation would have been more difficult if these had been included. Finally, it is broadly recognised that the SARS-CoV-2 viral swabs have a sensitivity of approximately $70 \%^{39}$ and so, by using swab results to define the patient cohort for this study it is possible some cases may have been missed. Within the conducting trust, however, it was common practice to take multiple swabs from patients who had an initial negative result but had a clinical phenotype highly likely to represent SARS-CoV-2 infection. As such, it is hoped the impact of this inclusion criteria is small.

\section{CONCLUSION}

The study demonstrated a TTE service in a UK district general hospital can be adapted to meet the demands of a rapidly progressing international health crisis. Our echocardiographic data observed right heart dilation and strain most commonly on our small cohort, this is hypothesised to be related to raised pulmonary artery pressures. There was no association between SARS-CoV-2 patients' echocardiographic findings and mortality, unlike other papers recently published.

\section{Twitter Christopher James McAloon @DrChrisMcAloon}

Contributors The idea for this article was contributed by CJM who also oversaw the creation of the article. Data were collected by RLC, MG and HW. The paper was written and the statistics completed by RLC. All other authors contributed to the echocardiographic service and to the coordination of data collection.

Funding The authors have not declared a specific grant for this research from any funding agency in the public, commercial or not-for-profit sectors.

Competing interests None declared.

Patient consent for publication Not required.

Ethics approval The internal audit and governance committee gave permission to undertake this study.

Provenance and peer review Not commissioned; externally peer reviewed.

Data availability statement All data relevant to the study are included in the article or uploaded as online supplemental information. Discussion of the data used is welcome.

Open access This is an open access article distributed in accordance with the Creative Commons Attribution Non Commercial (CC BY-NC 4.0) license, which permits others to distribute, remix, adapt, build upon this work non-commercially, and license their derivative works on different terms, provided the original work is properly cited, appropriate credit is given, any changes made indicated, and the use is non-commercial. See: http://creativecommons.org/licenses/by-nc/4.0/.

ORCID iD

Rebecca Lucy Crook http://orcid.org/0000-0001-6189-5539 


\section{REFERENCES}

1 World Health Organisation. Who coronavirus disease (COVID-19) Dashboard. Available: https://covid19.who.int/?gclid=CjOKCQjw o6D4BRDgARIsAA6uN1_sfL3daR1IWE_9uZxcHs2rkqVLWIrITapn0nI yphYyJyZuhDu-Lt4aAi6UEALw_wcB [Accessed 10 Jul 2020].

2 Wang D, Hu B, Hu C, et al. Clinical characteristics of 138 hospitalized patients with 2019 novel coronavirus-infected pneumonia in Wuhan, China. JAMA 2020;323:1061-9.

3 Ruan Q, Yang K, Wang W, et al. Clinical predictors of mortality due to COVID-19 based on an analysis of data of 150 patients from Wuhan, China. Intensive Care Med 2020;46:846-8.

4 Chen T, Wu D, Chen H, et al. Clinical characteristics of 113 deceased patients with coronavirus disease 2019: retrospective study. BMJ 2020;368:m1091.

5 Office of National Statistics. Deaths registered Weekly in England and Wales, provisional. Available: https://www.ons.gov.uk/peop lepopulationandcommunity/birthsdeathsandmarriages/deaths/ bulletins/deathsregisteredweeklyinenglandandwalesprovisional/ weekending3april2020 [Accessed 20 Apr 2020].

$6 \mathrm{Wu} \mathrm{Z}$, McGoogan JM. Characteristics of and important lessons from the coronavirus disease 2019 (COVID-19) outbreak in China: summary of a report of 72314 cases from the Chinese center for disease control and prevention. JAMA 2020.

7 Zhou F, Yu T, Du R, et al. Clinical course and risk factors for mortality of adult inpatients with COVID-19 in Wuhan, China: a retrospective cohort study. Lancet 2020;395:1054-62.

8 Cristelo C, Azevedo C, Marques JM, et al. SARS-CoV-2 and diabetes: new challenges for the disease. Diabetes Res Clin Pract 2020;164:108228.

9 Li B, Yang J, Zhao F, et al. Prevalence and impact of cardiovascular metabolic diseases on COVID-19 in China. Clin Res Cardiol 2020;109:531-8.

10 Shi S, Qin M, Shen B. Association of Cardiac Injury With Mortality in Hospitalized Patients With COVID-19 in Wuhan, China. JAMA Cardiol (Published Online First: 25 March 2020).

11 Huang C, Wang Y, Li X, et al. Clinical features of patients infected with 2019 novel coronavirus in Wuhan, China. The Lancet 2020;395:497-506.

12 Guo T, Fan Y, Chen M, et al. Cardiovascular implications of fatal outcomes of patients with coronavirus disease 2019 (COVID-19). JAMA Cardiol 2020;5:811.

13 Drake DH, De Bonis M, Covella M, et al. Echocardiography in pandemic: front-line perspective, expanding role of ultrasound, and ethics of resource allocation. J Am Soc Echocardiogr 2020;33:683-9.

14 Skulstad H, Cosyns B, Popescu BA, et al. COVID-19 pandemic and cardiac imaging: EACVI recommendations on precautions, indications, prioritization, and protection for patients and healthcare personnel. Eur Heart J Cardiovasc Imaging 2020;21:592-8.

15 European Society of Cardiology. Esc guidance for the diagnosis and management of cv disease during the COVID-19 pandemic. Available: https://www.escardio.org/Education/COVID-19-andCardiology/ESC-COVID-19-Guidance [Accessed 15 Jun 2020].

16 World Health Organisation. Laboratory testing for coronavirus disease 2019 (COVID-19) in suspected human cases: interim guidance, 2020. Available: https://apps.who.int/iris/handle/10665/ 331329 [Accessed 10 Apr 2020].

17 British Society of Echocardiography. Transthoracic echocardiograms during COVID-19 pandemic. Available: https://www.bsecho.org/ Common/Uploaded\%20files/Education/COVID-19/COVID-19\% 20TTE\%20pathway.pdf [Accessed 10 Apr 2020].

18 British Society of Echocardiography. Level 1 minimum dataset. Available: https://www.bsecho.org/Public/Accreditation/Personal-
accreditation/Level-1/Public/Accreditation/Accreditation-subpages/ Personal-accreditation-subpages/Level-1-accreditation.aspx? hkey $=6099 \mathrm{~b} 4 \mathrm{~b} 8-5 \mathrm{cb} 9-4425-\mathrm{a} 201-1874$ aadcb73f [Accessed $10 \mathrm{Apr}$ 2020].

19 Nagata Y, Kado Y, Onoue T, et al. Impact of image quality on reliability of the measurements of left ventricular systolic function and global longitudinal strain in 2D echocardiography. Echo Res Pract 2018;5:27-39.

20 Ward RP, Lee L, Ward TJ, et al. Utilization and appropriateness of transthoracic echocardiography in response to the COVID-19 pandemic. J Am Soc Echocardiogr 2020;33:690-1.

21 Mahmoud-Elsayed HM, Moody WE, Bradlow WM. Echocardiographic findings in Covid-19 pneumonia. CJC Open 2020.

22 Deng Q, Hu B, Zhang Y, et al. Suspected myocardial injury in patients with COVID-19: evidence from front-line clinical observation in Wuhan, China. Int J Cardiol 2020;311:116-21.

23 Szekely Y, Lichter Y, Taieb P. The spectrum of cardiac manifestations in coronavirus disease 2019 (COVID-19) - a systematic echocardiographic study. Circulation 2020.

24 Ye Q, Wang B, Mao J. The pathogenesis and treatment of the 'Cytokine Storm' in COVID-19. J Infect 2020;80:607-13.

25 Coperchini F, Chiovato L, Croce L, et al. The cytokine storm in COVID-19: an overview of the involvement of the chemokine/ chemokine-receptor system. Cytokine Growth Factor Rev 2020;53:25-32.

26 Singh R, Kashyap R, Hutton A, et al. A review of cardiac complications in coronavirus disease 2019. Cureus 2020;12:e8034..

27 Madjid M, Safavi-Naeini P, Solomon SD, et al. Potential effects of coronaviruses on the cardiovascular system. JAMA Cardiol 2020;5:831.

28 Bansal M. Cardiovascular disease and COVID-19. Diabetes Metab Syndr 2020;14:247-50.

29 Kang Y, Chen T, Mui D, et al. Cardiovascular manifestations and treatment considerations in COVID-19. Heart 2020;106:1132-41.

30 Akhmerov A, Marbán E. COVID-19 and the heart. Circ Res 2020;126:1443-55.

31 Atri D, Siddiqi K, Lang JP. Basic virology, epidemiology, cardiac manifestations, and potential therapeutic strategies. JACC Basic Trans Sci 2020;5:518-36.

32 Kuba K, Imai Y, Rao S, et al. A crucial role of angiotensin converting enzyme 2 (ACE2) in SARS coronavirus-induced lung injury. Nat Med 2005;11:875-9.

33 Xiao X, Chakraborti S, Dimitrov AS, et al. The SARS-CoV S glycoprotein: expression and functional characterization. Biochem Biophys Res Commun 2003;312:1159-64.

34 Farcas GA, Poutanen SM, Mazzulli T, et al. Fatal severe acute respiratory syndrome is associated with multiorgan involvement by coronavirus. J Infect Dis 2005;191:193-7.

35 Zhao J, Zhou G, Sun Y. Clinical pathology and pathogenesis of severe acute respiratory syndrome. Chinese Journal of Experimental and Clinical Virology 2020;17:217-21.

36 Bojkova D, Wagner JUG, Shumliakivska M, et al. SARS-CoV-2 infects and induces cytotoxic effects in human cardiomyocytes. Cardiovasc Res 2020;116:2207-15.

37 Zhao M, Wang M, Zhang J, et al. Advances in the relationship between coronavirus infection and cardiovascular diseases. Biomed Pharmacother 2020;127:110230.

38 GOV.UK. Coronavirus (COVID-19) in the UK. Available: https:// coronavirus.data.gov.uk/\#category=regions\&map=rate [Accessed 10 Jun 2020].

39 Watson J, Whiting PF, Brush JE. Interpreting a covid-19 test result. BMJ 2020;369:m1808. 